\title{
Comments to: risk factors for late defecation and its association with the outcomes of critically ill patients: a retrospective observational study
}

\author{
Dominique Prat $^{1}$ and Benjamin Sztrymf ${ }^{1,2^{*}}$
}

See related Research by Fukuda et al., http://jintensivecare.biomedcentral.com/articles/10.1186/s40560-016-0156-1

\begin{abstract}
In a previous retrospective work, it has been postulated that early enteral nutrition was a protective factor against late defecation and its subsequent consequences in critically ill patients. We raise concerns about methodological issues limiting the conclusions.
\end{abstract}

Keywords: Critical care, Defecation, Outcome

\section{Findings}

We read with great interest the article by Fukuda et al. dealing with the risk factors for late defecation in critical care patients [1]. The results suggest an independent association between late enteral nutrition (i.e., more than 2 days after admission) and late defecation (i.e., 5 days or more after admission). However, some points might require clarification. First, the authors state that the first intervention to promote defection was earlier in the early as compared to late defecation group (3 (2-4) vs. $6(4-7)$ days, $p<0.001)$. Nevertheless, they did not include this variable in their univariate and multivariate analysis of factor influencing the delay of defecation because they found out that the interventions was associated with late defecation. It is stated that this was a result of physicians concern of delayed transit. Nevertheless, patients in the early defecation group received intervention much sooner after physician evaluation. Though fewer patients received interventions in the early defecation subgroup, it still represents $50 \%$ of the cohort. Therefore, we would like to underline that the timing of intervention might also have been considered for the multivariate analysis. Second, though not specifically stated, exclusion criteria do not seem to encompass some conditions clearly affecting transit such as pancreatitis, postpartum patients, hypothyroidism, or occlusive syndrome. We wonder if such patients might have been included in the study, therefore potentially impacting the results. Third, the article does not provide clear explanations for the late beginning of enteral nutrition. Although it is stated in the discussion that some regimens of nutrition are usual in the investigating centre, no protocol seemed to be followed, and the reasons of late enteral nutrition beginning might have been influenced by the attending physician own decision and beliefs. Fourth, only $33 / 282$ patients harbored infection, which seems to be unexpectedly low for a 20 bed ICU after a year of study.

* Correspondence: benjamin.sztrymf@abc.aphp.fr

${ }^{1}$ Service de Réanimation polyvalente et surveillance continue, Assistance

Publique-Hôpitaux de Paris, Hôpital Antoine Béclère, Université Paris Sud, Clamart F-92400, France

${ }^{2}$ Institut National de la Santé et de la Recherche Médicale, INSERM U999, Le

Plessis Robinson F-92060, France 


\section{Author response}

\section{Shinya Fukuda, Takashi Miyauchi, Motoki Fujita, Yasutaka Oda, Masaki Todani, Yoshikatsu Kawamura, Kotaro Kaneda and Ryosuke Tsuruta}

We appreciate Dr. Dominique's comments regarding our study [1], "Risk factors for late defecation and its association with the outcomes of critically ill patients: a retrospective observational study".

The issue of "intervention" was discussed among the authors. We have performed multivariable analysis in which we defined early and late intervention as $\leq 3$ days and $>3$ days after admission, respectively, and included these as explanatory factors. We found that late intervention was a risk factor for late defecation (odds ratio, 3.00, $95 \%$ confidence interval, 1.50 to $6.02, P=0.002$ ). This did not alter our main findings.

However, unlike other factors, such as sedation, late enteral nutrition, and surgery, it is unsurprising that intervention is closely related to the time to defecation because interventions are usually performed in patients with delayed defecation. Accordingly, our statistician recommended excluding "intervention" from the multivariable analysis.

These results also raise the possibility that early intervention could improve the outcome of patients. This may be true, but we are concerned that discussing this issue could be misleading or alter the conclusions. Furthermore, the study was not designed to address this possibility. A prospective study is necessary to investigate the effects of interventions on the outcomes of critically ill patients being treated in an intensive care unit (ICU).

Our patients included two with pancreatitis and one with paralytic ileus. Nevertheless, it is conceivable that the risk factors identified in our study are also associated with late defecation in patients with these or similar illnesses. We think that patients with direct occlusion of the intestine should be excluded, but patients with indirect dysfunction of intestinal transit can be included in studies such as ours.

As Dr. Dominique has suggested, we should report the timing of enteral nutrition. Because the nutrition regimen in our ICU is not strictly timed, each attending physician determines when to administer nutrition based on various factors, such as the stability of vital signs, the presence of bowel sounds, and the gastric residual volume. All of the physicians in our ICU recognize the importance of enteral nutrition.

We also placed patients with a primary source of infection in an "infection" group. Infection was diagnosed based on the patient's present and past medical history, physical findings, bacterial cultivation, and biochemical and radiographic findings. Careful examination of the source of infection may be associated with the small number of infectious patients included in our study. In addition, because our emergency ICU accepts severe outpatients, only approximately 30 infectious patients are admitted per year. Infectious patients who died or who were discharged $<6$ days after ICU admission were excluded from our study.

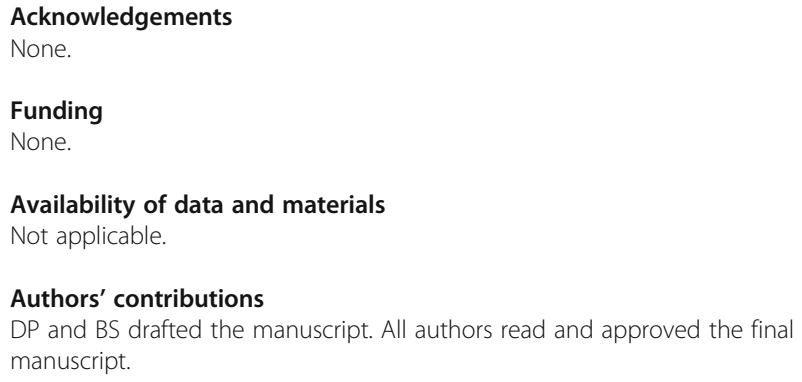

Received: 3 June 2016 Accepted: 11 July 2016

Published online: 19 July 2016

References

1. Fukuda S, Miyauchi T, Fujita M, et al. Risk factors for late defecation and its association with the outcomes of critically ill patients: a retrospective observational study. J intensive Care. 2016;4:33.

Submit your next manuscript to BioMed Central and we will help you at every step:

- We accept pre-submission inquiries

- Our selector tool helps you to find the most relevant journal

- We provide round the clock customer support

- Convenient online submission

- Thorough peer review

- Inclusion in PubMed and all major indexing services

- Maximum visibility for your research

Submit your manuscript at www.biomedcentral.com/submit 